
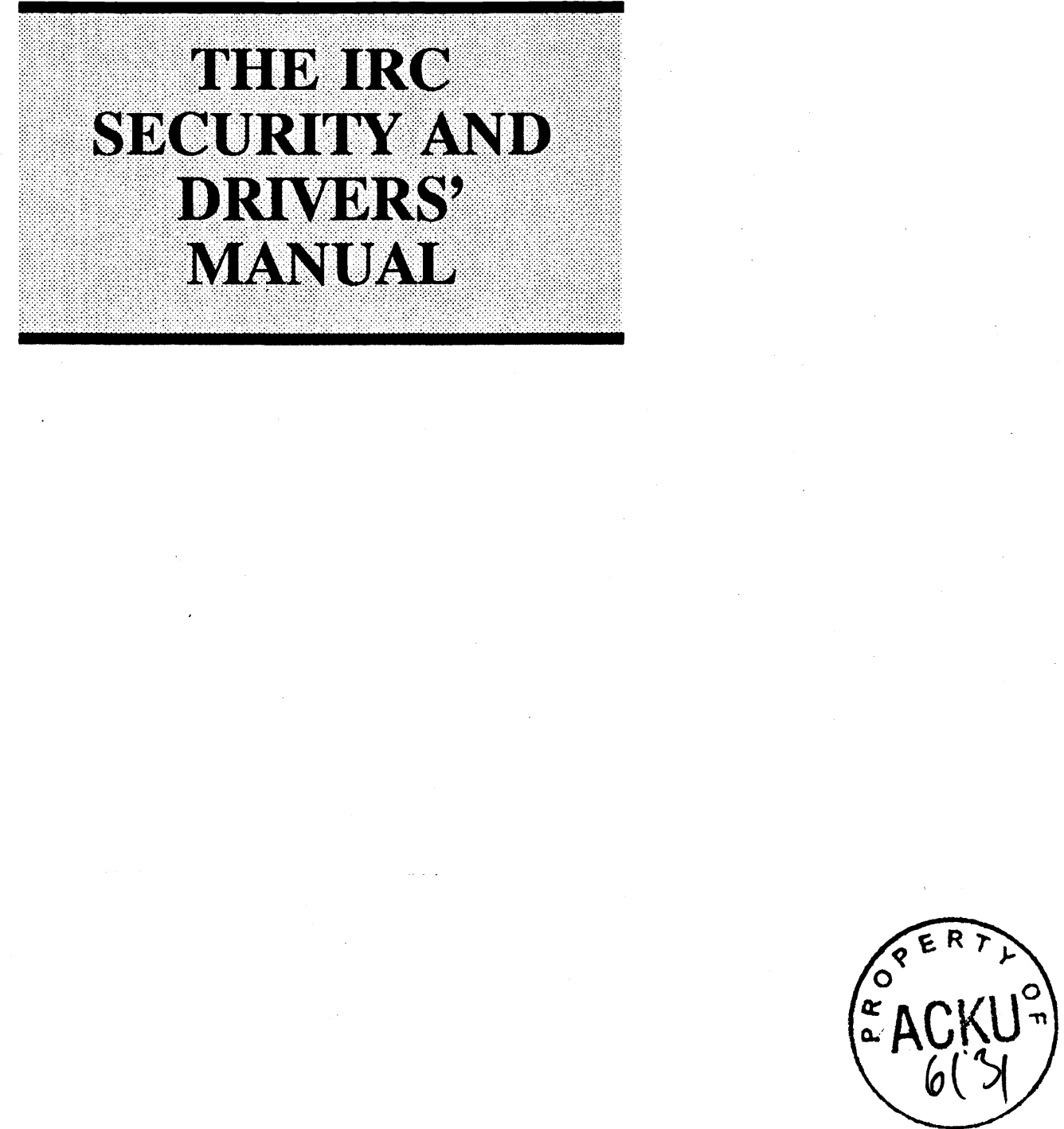


\section{**** TABLE OF CONTENTS}

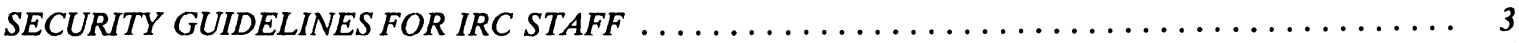

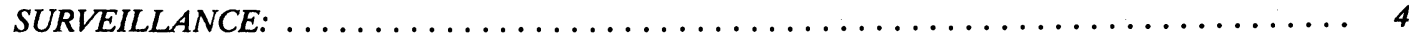

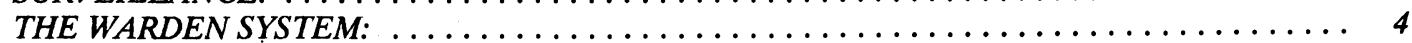

SECURITY INSTRUCTIONS FOR IRC CHOWKIDARS: $\ldots \ldots \ldots \ldots \ldots \ldots \ldots \ldots \ldots \ldots \ldots$ RULES APPLICABLE TO ALL CHOWKIDARS .................... 4 RULES PARTICULAR TO STAFF HOUSE CHOWKIDARS $\ldots \ldots \ldots \ldots \ldots \ldots \ldots \ldots \ldots$

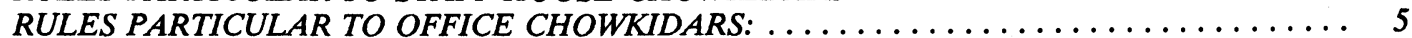

DRIVERS' INSTRUCTIONS AND SECURITY GUIDELINES $\ldots \ldots \ldots \ldots \ldots \ldots \ldots \ldots \ldots \ldots$

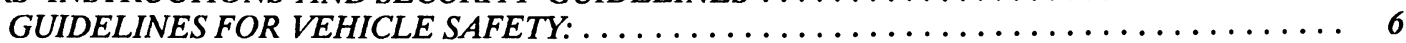
GUIDELINES FOR VEHICLE SECURITY: $\ldots \ldots \ldots \ldots \ldots \ldots \ldots \ldots \ldots \ldots \ldots \ldots \ldots \ldots$ Appendix A: Emergency Contact Numbers .......................... 7

Appendix B: Important Telephone Numbers $\ldots \ldots \ldots \ldots \ldots \ldots \ldots \ldots \ldots \ldots \ldots \ldots \ldots \ldots, 8$ 


\section{SECURITY GUIDELINES FOR IRC STAFF}

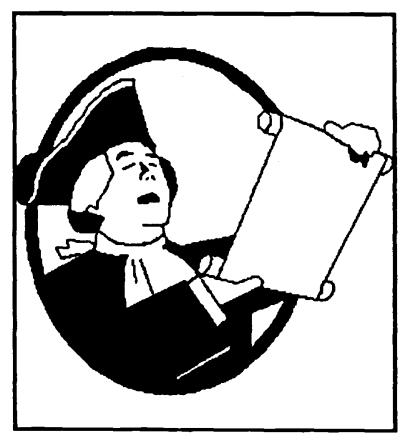

Security must be an ongoing concern for IRC staff in Peshawar. Over the years there have been a number of hostile threats and actions against foreign presence in Pakistan. While robberies, burglaries and rape are virtually unheard of, most actions against foreigners in Pakistan are politically-inspired and thus more likely to be specifically-targeted acts of intimidation, kidnapping or terrorism. Actions have included the burning of the American Embassy in 1979, kidnapping of aid workers and death threats to agency employees. It should be noted that threats are not limited to international staff and in many instances, local staff face graver security problems than expatriates.

This manual is intended to provide guidelines and policy outlines which are designed to enhance the security of IRC staff. In almost all instances, however, the individual is the key factor in assuring security. Your profile and the priority you attach to your personal safety is paramount.

IRC international staff are urged to observe the following security guidelines:

1. Avoid routine travel habits: Vary your arrival and departure times and routes to and from work as well as lunch hours or social routines.

2. Keep colleagues/friends informed: Always notify someone of where you are going and for how long, even on the shortest trips to the store. For longer trips outside of town, put your travel plans in writing and give it to one of your house-mates or colleagues.

3. Keep a low profile: Avoid dress and/or behavior which attracts attention to you. Walking or jogging on the streets of University Town is discouraged. Men should wear a shirt and long pants and women should wear a shalwar kameez and chaddar in public. Women should be aware that signs of recognition or familiarity can be misconstrued and should remain aloof and business-like in exchanges with strangers or shopkeepers.

4. Be alert for surveillance: (see below) If you see the same stranger in several places, if a stranger inquires about you (perhaps asking your housekeeper or driver), if a vehicle follows you or if an acquaintance seems suspiciously curious about you, notify the Administrative Coordinator, providing as much detail as possible. Never confront someone who you believe is conducting surveillance.

5. Provide information on a need-to-know basis only: Do not share personal information (addresses, telephone numbers, travel plans, etc.) or information about your colleagues to those who have no need to know the information, including housekeepers, drivers, etc.

6. Avoid high-risk places: Avoid public demonstrations, large crowds and tribal areas.

7. Know local safe havens: Take note of places where you could run for escape or assistance in an emergency. Such places may include hospitals, police stations, government facilities, the American Club or homes of trusted people.

8. Keep important phone numbers readily available: Including copies in your wallet or purse and next to your telephone. Numbers should include police, fire department, consulate, IRC Offices and the IRC Director and Deputy Directors' home numbers. Important numbers are included in the appendix.

9. Keep house/vehicle doors and windows locked at all times: even when you are in your home or car.

10. Do not leave IRC vehicles unattended: Per IRC policy, an IRC driver must be used when going anywhere where the vehicle must be left unattended. In general, driving by international staff is discouraged and must be limited to Peshawar. (International staff wishing to drive must hold a valid Pakistani license).

11. Stress your concern with security to your staff: Especially housekeepers and drivers. They should never give information to strangers, allow unidentified persons to enter your compound or accept unexpected deliveries. Never allow or ask your staff to violate security guidelines such as by asking a guard to run an errand or ignoring a sleeping guard. Know your staff by name.

12. Never accept unexpected packages: or packages whose contents or origins are unclear. If a suspicious package is dropped off, do not touch it. Contact the Admin Coordinator, local bomb squad or police (see appendix).

13. Keep ample distance between vehicles on the road: Do not drive, or allow IRC drivers to drive, closer than one car length per $10 \mathrm{kph}$ behind the car in front of yours, or come to a stop within less than a car length. This provides room to escape an entrapment...as well as being a safe driving practice. 


\section{SURVEILLANCE:}

A period of surveillance ranging from a few days to several months precedes most targeted hostile acts. Surveillance is used to identify a target and to note routine travel patterns, routes and times in order to prepare a kidnapping or assassination attempt. When a target is identified, a plan is usually set up around a pre-specified spot that the target is expected to enter upon. As noted above, the best way to foil such an attack is to be unpredictable by alternating your routes and times. It is also valuable to be aware of surveillance:

\section{Signs of surveillance:}

- seeing the same stranger in different places,

- a stranger inquiring about you,

- telephone calls which begin with 'who is speaking'

\section{- strangers or acquaintances who seem overly curious and friendly,}

2. Baiting a suspect: If you think you are under surveillance but are not in immediate danger, you may try baiting the suspect by dropping an envelope or paper on the ground to see if the suspect retrieves it, or by taking a circuitous route to see if you are being followed.

3. Escaping danger: If you believe that you are under immediate danger, draw as much attention as possible, create a scene, scream and look for a safe haven.

4. Take note of possible surveillance: Note vehicle description and license plate numbers and/or the dress, features and as much identifying information as possible of those who you suspect of surveillance. Provide the Administrative Coordinator with this information so that he can combine it with other reports and/or inform the security staff to be on the lookout for vehicles or individuals described.

5. If attacked, get off the X: As noted above, surveillance can culminate in an attack typically at a predetermined spot which the targeted person is expected to cross at a routine time. In almost all instances where the targeted person has been able to get off of this spot, or 'the X', the attacker's plans are foiled.

\section{THE WARDEN SYSTEM:}

IRC is an active participant in the American Consulate's Warden System. The system is a network of telephones, radios and, if necessary, couriers, through which information can flow in an emergency. Although the system is coordinated by the American Consulate, it is intended to include any foreign nationals who may be subject to security problems.

In the event that the warden system is put into action, the Consulate contacts IRC's warden (the director) or an alternate (a deputy director or other staff person) with an important message. The IRC warden then places phone calls to IRC housing compounds and/or offices, asking persons at each location to pass the message on to the other staff living/working at that location. A current calling list is circulated to all international staff on a routine basis (see Appendix A for an outline).

In the event that telephones are out of order, IRC currently has four radios on frequency with the Consulate. You should familiarize yourself with who the radio holders are. The radios can also be used for contacting the consulate in an emergency.

\section{SECURITY INSTRUCTIONS FOR IRC CHOWKIDARS:}

The following are IRC security instructions for chowkidars. For ease of reference, they have been divided into three areas: rules that apply to all chowkidars, those that apply to staff house chowkidars and those that apply to chowkidars at IRC offices. An Urdu/Pushto version of these instructions are with the chowkidars. Failure to carry out these duties or any contravention to these instructions can mean immediate termination of the chowkidar concerned.

\section{RULES APPLICABLE TO ALL CHOWKIDARS:}

1. Keep the gate closed: except to admit authorized visitors.

2. Identify visitors before allowing them to enter the compound:

- Check IRC I.D. cards for unknown persons claiming to be IRC employees: is the photo correct? Has the plastic cover been tampered with? Is the director's signature authentic? If there is any doubt, keep the card and deny admission. 
- Except for verified IRC employees or known visitors, visitors should be asked to wait at the gate until the person they are seeking authorizes their entry.

3. Make routine rounds: Guards should circuit the premises every 30 minutes except at offices during office timings when other staff are present. The circuit should include a look around the building and stepping outside and noting the outer wall and any

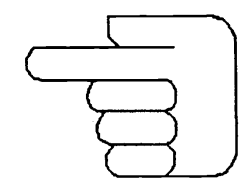
unusual street activity.

4. Never leave the premises without a relief guard in place: Under no circumstances should the guard run errands for staff or residents, go out to eat or pray or leave one's duty before a replacement guard has arrived. Guards should pray at their post.

5. Wear an IRC uniform, name plate and ID card at all times: Guards should not arrive for duty in personal clothing. The name plate and IRC ID card must be worn and clearly visible on the shirt or coat pocket at all times while on duty.

6. Maintain the following inventory:

- a whistle, which is kept on his person,

- a flashlight with adequate batteries

- a list of emergency telephone numbers

7. Refrain from entering the office or house being guarded: Guards must not accept invitations to enter the house or office being guarded except to make emergency phone calls. Guards are not permittèd to bathe during duty.

8. Remain awake and fully observant: Sleeping on duty is strictly forbidden.

9. Morning and afternoon shift guards must be present at attendance parade and at post at least ten minutes before their duty begins.

10. Maintain the building's water supply through timely operation of the water pump and a daily check of the pilot light on the geezer (water heater).

11. Guards are strictly forbidden to enter discussions or give out information regarding the staff or residents of the building. Suspicious inquiries about the building or its occupants should be reported to the Administrative Coordinator.

12. Notify the security officer of:

- suspicious persons or activities

- items missing from the premises

13. Inform residents and/or proper authorities in case of emergency.

\section{RULES PARTICULAR TO STAFF HOUSE CHOWKIDARS:}

1. Do not accept strange parcels, or mail which is unaccompanied or delivered by unidentified personnel. If you do not know its origin, first consult the person to whom it is addressed. If he/she does not recognize it, do not hesitate to call the police and Bomb Disposal Squad. If residents are not available, call the Admin. Coordinator.

2. Do not permit any private vehicle to enter without the prior permission of the resident of the house.

3. House gates should remain closed and bolted whenever chowkidars say their prayers. It is preferable if the housekeeper or gardener can attend the gate during prayers.

4. Respect the privacy of the resident:

5. Report burned out security lights to resident daily until repaired.

\section{RULES PARTICULAR TO OFFICE CHOWKIDARS:}

1. Search all unknown men coming into the building. Searches should include briefcases, bags or other items being carried as well as a cursory body check. If available, a metal detector should be used instead of a body check. Inspection should be identical for Pakistanis, Afghans, expatriates and unknown staff members alike.

2. Search unknown women's bags: Visually and/or with a metal detector if available.

3. Check all vehicles seeking entry into the premises by stopping them at the gate and inspecting the undercarriage with a mirror and looking over the interior of the car. Non-IRC drivers should be searched.

4. Outside chowkidars should walk about continuously. He should be attentive to all traffic and pedestrians. Any questionable vehicle should be approached and investigated.

5. Outside chowkidars should note all unfamiliar cars parked near IRC offices or residences. Suspicious vehicles should be reported.

6. Guests of cooks, chowkidars \& gardeners must not be granted permission to enter the grounds. 


\section{DRIVERS' INSTRUCTIONS AND SECURITY GUIDELINES}

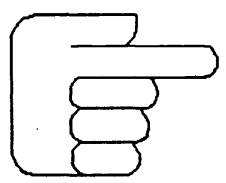

The following instructions are for all IRC Vehicle Drivers. Again these are translated into Urdu/Pushto for the benefit of the drivers. Drivers' failure to carry out these instructions should be reported to the Admin Coordinator or concerned Program Coordinator. The instructions are divided between safety, security and maintenance.

\section{GUIDELINES FOR VEHICLE SAFETY:}

\section{Maximum speed: $60 \mathrm{KPH}$ in town, $90 \mathrm{KPH}$ out of town.}

2. Minimum distance between cars: 1 vehicle length per each $10 \mathrm{KPH}$. A minimum of 1 vehicle length should be maintained while stopped to allow room for emergency manoeuver.

3. Never overtake on curves, hills or in such a way as to require cars to be three abreast (on two lanes).

4. Conduct a daily maintenance check including oil and water levels, tire pressure and general inspection of engine and undercarriage. Correct or report mechanical problems as necessary.

5. Report any damage or accident immediately to the Administrative Coordinator.

6. Use of seat belts is to be encouraged.

\section{GUIDELINES FOR VEHICLE SECURITY:}

1. Alternate routes on routine trips.

2. Minimum distance between cars: 1 vehicle length per each $10 \mathrm{KPH}$. A minimum of 1 vehicle length should be maintained while stopped to allow room for emergency manoeuver.

3. Lock doors when in or out of the car.

4. Keep fuel tank full: Fuel vapors and not liquid fuel are most explosive, thus an empty tank is more dangerous than a full tank. Fuel shortages also make this step prudent.

5. Never leave a vehicle unguarded: Inside office or residential compounds or in front of the American Club and American Consulate should be adequately guarded.

6. Do not stop in tribal areas. IRC policy explicitly forbids unauthorized trips to tribal areas.

7. Drive courteously. Do not attract attention by excessively aggressive driving.

8. Know alternate routes to your destination and be aware of you location.

9. Do not stop for to assist other motorists or to pick up riders.

10. Monitor rear-view mirrors. Note the plate numbers and description of any vehicle you feel may be following you and head for a safe haven.

11. Be extra alert in any road blockage and be prepared to take evasive action.

12. Conduct vehicle bomb search if security precautions are in effect, or if you have reason to believe your car may have been tampered with:

- look inside and under the dash and circle the vehicle looking underneath, at the gas filler cap and in the grill. Look for wires, bits of tape, string or other foreign matter. Look for signs of forced entry such as scratches or pry marks around the doors, hood, windows, etc. Look under the vehicle and check the exhaust/muffler system, gas tank and all around the tyres. Check under the hood for foreign devices attached to the clutch, brake, accelerator, battery or steering linkage.

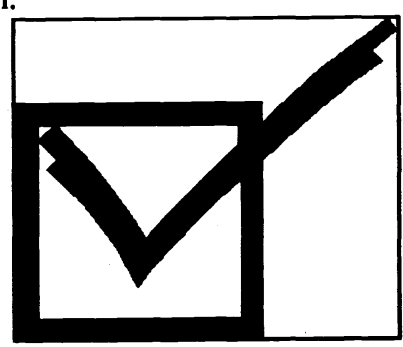


Appendix A:

Emergency Contact Numbers

\section{CONIFIDIENTIAL}

\section{NAME}

Randy Martin

Toc Dunlap

Sher Haider

Dr. Hassani

William Thompson

Main Office Direct

Univ. Town Police

Emergency Police

U.S. Consulate

Principal Office

\section{OFFICE TELEPHONE}

41274, 41845, 43242, 43668,

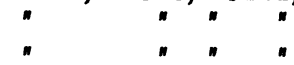

41944

41560,43310

840203

40808

212222, 213333, 213222

279801-3

276316
RESIDENCE NO.

40341/840572

840361

$43036 / 43836$

44724

40671

\section{WARDEN SYSTEM}

In case there is an emergency of which Country Director is informed by the Consulate, the following houses will be contacted by Randy and Toc. In the event that either Randy and/or Toc are unavailable, Villy/Sher will serve as alternates. During working hours, staff will be contacted at their respective offices.

Randy Martin (40341, 840572):

1. $84 d$ S.A.Q. Rd.

2. $9 a, 9 b, 9 c$ University Rd.

Toc Dunlap (840361):

3. $12 c$ \& 12d Chinar Rd.

4. 35B Chinar Lane

Keep this list near your telephone at home.
Number

41350

40671, 40973, 841138

41228 (same for both)

44352 


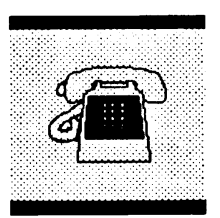

B Bomb Disposal Squad In-charge

Office 278092

Res. 274025

E Electricity Complaint

41060

F $\quad$ Fire Brigade (City)

64279

Fire Brigade (Univ. Town) 41060

H Houses:

Randy

40341, 840572

Sher Haider

43036, 43836

Riaz (Maintenance Supervisor) 276443

Naseer (Driver Supervisor) 272604

Hospitals:

Lady Reading Hospital $210031-39$

Khyber Teaching Hospital $\quad 40271-78$

I.C.R.C Hospital

40498

0 Offices:
IRC Main Office
American Consulate
American Club
41274, 43242, 41845, 43668
279801 -- 03
41321
American Embassy (Islamabad) (051) 824857, 826161
Principal Office
276316 (Residence)

P Police:

Emergency Police

Univ. Town Police

$212222,213333,213222$

40358

S Sui Gas Complaint Office

272511,272512

T Telephone:

\begin{tabular}{ll}
\hline Enquiry & 17 \\
Complaint & 18 \\
Trunk Booking & 109 \\
Trunk Enquiry \& complaint & 103 \\
Overseas Booking & 102 \\
Overseas Enquiry & 104
\end{tabular}

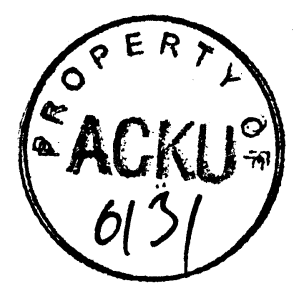

